\title{
Irritable bowel syndrome: from young to older age
}

\author{
Max Schmulson ${ }^{1,2^{*}}$ and Miguel Saps ${ }^{3}$
}

${ }^{1}$ Laboratorio de Hígado, Páncreas y Motilidad, Unidad de Investigación en Medicina Experimental, Facultad de Medicina-Universidad Nacional Autónoma de

México, Hospital General de México, Dr. Eduardo Liceaga; ${ }^{2}$ Gastroenterología y Endoscopía en PMG, Centro Médico ABC, Mexico City, Mexico; ${ }^{3}$ Department

of Pediatrics, Division of Pediatric Gastroenterology, Hepatology and Nutrition, University of Miami, Miller School of Medicine, Miami, Florida, USA.

\section{RESUMEN}

El síndrome de intestino irritable (SII) puede aparecer en la infancia y continuar en la edad adulta y factores de riesgo tempranos de la vida han sido asociados con el desarrollo del SII más tarde en la adultez; sin embargo, se conoce poco sobre la transición infancia-edad adulta en este trastorno. Por lo anterior nuestro objetivo fue revisar: (1) Factores de riesgo tempranos de la vida que contribuyen al desarrollo de SII en la adultez; (2) la transición de la atención médica; (3) la historia natural del SII y la estabilidad de los síntomas; (4) la prevalencia del SII en los adultos jóvenes hasta la madurez; (5) el tratamiento en la madurez; y (6) medidas preventivas. De acuerdo con lo anterior, múltiples factores tempranos de la vida han sido relacionados con el SII en la edad adulta incluyendo dolor abdominal crónico, aprendizaje social de la conducta de enfermedad, trauma en la infancia y la niñez, un peso al nacer < 1500 g, succión gástrica y parto por cesárea, (pueden alterar la colonización de la microbiota intestinal y la inmunorregulación; desaparición del microbioma), historia de abuso, deprivación parenteral, y bajo nivel socioeconómico. Existe controversia de si las infecciones entéricas tempranas en la vida pueden ser protectoras del posterior desarrollo del SII post-infeccioso así como la exposición a mascotas y la vivienda con alta densidad (factores de higiene). En cuanto a la transición en la atención médica -crucial en el manejo de trastornos crónicos-, no hay experiencia en SII como ocurre con otras enfermedades. Y en cuanto a si la prevalencia del SII incrementa o disminuye con la edad, los datos también son inconsistente; sin embargo, al menos una tercera parte de los pacientes con SII se vuelven asintomáticos, una tercera parte permanecen estables y el resto cambian

\footnotetext{
Correspondence to:

*Max Schmulson

Laboratorio de Hígado, Páncreas y Motilidad

Unidad de Investigación en Medicina Experimental

Facultad de Medicina

Universidad Nacional Autónoma de México

Hospital General de México. Dr. Eduardo Liceaga

Dr. Balmis \#148. Col. Doctores

C.P. 06726, Mexico City, México

E-mail:maxjulio@prodigy.net.mx
}

Received in original form: 16-01-2019

Accepted in final form: 12-02-2019

DOI: 10.24875/NGL.19000024 
a otro trastorno de la interacción intestino-cerebro a lo largo de la vida. Así mismo, las aflicciones emocionales en los pacientes con SII con comorbilidades médicas varían con la edad, con mayores niveles de ansiedad y depresión entre los pacientes jóvenes en comparación con los pacientes mayores. Finalmente, el tratamiento del SII a mayor edad es similar al de los pacientes jóvenes. En conclusión, los factores de riesgo tempranos de la vida deben ser identificados para establecer medidas preventivas contra el desarrollo del SII en la edad adulta. Se requiere desarrollar guías sobre la transición de la atención médica en el manejo de pacientes con SII y se necesita realizar ajustes al tratamiento de acuerdo con la presencia de comorbilidades. (NeuroGastroLatam Rev. 2018;:133-148)

Corresponding author: Max Schmulson,maxjulio@prodigy.net.mx

Palabras clave: Síndrome de intestino irritable. Factores de riesgo tempranos de la vida. Historia natural. Transición en la atención médica. Historia natural. Prevención.

\section{ABSTRACT}

Irritable bowel syndrome (IBS) may start in childhood and continues into adulthood and risk factors early in life (EL) have been associated with the development of IBS later in life; however, little is known about the childhood-adulthood transition. Therefore, we aimed at reviewing: (1) EL risk factors that contribute to IBS in adulthood; (2) transition of care; (3) the natural history and IBS-symptom stability; (4) prevalence of IBS from young adults to older age; (5) treatment in older age; and (6) preventive measurements. Accordingly, multiple EL factors have been related to IBS in adulthood including chronic abdominal pain, social learning of illness behavior, infantile and childhood trauma, birth weight $<1500 \mathrm{~g}$, gastric suctioning, and cesarean section (may impair gut-microbiota colonization and immunoregulation: disappearing microbiome), history of abuse, parental deprivation, and low socioeconomical level. There is a controversy of early enteric infections as these may be protective for post-infectious IBS later in life as well as for pet exposure and higher living density (hygiene factors). As for the transition of care from pediatric to adult care - crucial in managing a chronic disorder -, there is no experience in IBS as with other gastrointestinal diseases. Whether the prevalence of IBS increases or decreases with age, the data are inconsistent; however, at least a third of IBS patients become asymptomatic, a third remain stable, and the remaining turnover to another disorder of gut-brain interaction along time. Furthermore, distress among IBS patients with medical comorbidities varies with age, with higher levels of anxiety and depression among younger adults than older patients. Finally, treatment of IBS at an older age is similar to that in younger patients. In conclusions, EL risk factors need to be identified to establish preventive measurements for IBS later in life. A transition of care guidelines need to be developed for IBS and treatment adjustments are required according to the comorbidities.

Key words: Irritable bowel syndrome. Early life risk factors. Natural history. Transition of care. Prevention. 


\section{INTRODUCTION}

Irritable bowel syndrome (IBS) is a common functional gastrointestinal disorder, now called by Rome IV, disorders of gut-brain interaction $(\mathrm{DGBI})^{1}$, which will be used herein. The prevalence of IBS in adulthood around the world varies from $1.1 \%$ in France and Iran to $35.5 \%$ in Mexico ${ }^{2}$. However, IBS is a chronic disorder that may start in childhood and the prevalence in this stage of life has been reported at a range from $2.8 \%$ in the US to $22.6 \%$ in Turkey ${ }^{3}$. A previous metanalysis reported that IBS was the most frequent DGBI in childhood $8.8 \%$ (95\% confidence interval [CI] 6.2-11.9), and the prevalence across studies ranged widely from $1.6 \%$ to $41.2 \%$. Higher pooled prevalence rates were reported in South America $(16.8 \%)$ and Asia $(16.5 \%)$ compared to Europe $(10.5 \%)^{4}$. Although studies have analyzed the risk factors early in life (EL) that have been associated with the development of IBS later in life ${ }^{5,6}$, little is known about the childhood-adulthood transition. Therefore, in this paper, we aimed to review in short, the following: (1) early life risk factors that contribute to IBS in adulthood; (2) transition of care; (3) the natural history and symptom stability of IBS; (4) prevalence of IBS from young adults to older age; (5) treatment of IBS in older age; and (6) preventive measurements.

For the purpose of this review, young adult is defined as a person from the late teens or early twenties to their thirties and old age is a person 65 years old or older ${ }^{7,8}$ that leaves middle adulthood from 40 or 41 to 64 years of age $\mathrm{e}^{7,8}$.

\section{EARLY LIFE RISK FACTORS THAT CONTRIBUTE TO IBS IN ADULTHOOD AND TRANSITION OF CARE}

In 2008, Chitkara et al. conducted a systematic review of studies that analyzed early risk factors for the development of IBS in adolescents and adults ${ }^{9}$. Four groups of factors predicted IBS later in life; these included persistence of childhood gastrointestinal symptoms, social learning of illness behavior, affluent childhood socioeconomic status, and infantile and childhood trauma9. The first group comprehended the presence of chronic abdominal pain between 7 and 9 years of age, the presence of recurrent abdominal pain syndrome and constipation. In addition, it was found that abdominal pain before 5 years old was associated with increased symptom disability and lower perception of social competence in IBS-females, and with the perception of lower athletic competence in IBS-males 9 . Social learning of illness behavior had been demonstrated by a study showing that the proportion of dizygotic twins with IBS who had mothers with IBS was higher than the proportion of dizygotic twins who had cotwins with $\mathrm{IBS}^{10}$. As for affluent socioeconomic status in childhood, a higher social class in this period of time and a living density lower than one person per room (hygiene factor) ${ }^{11}$, were also associated with IBS in adulthood". In addition, early trauma including a birth weight $<1500 \mathrm{~g}$ was more likely associated with the development of IBS and the appearance of IBS at a younger age. Other factors included gastric suction at birth which can explain the later development of IBS by the disappearing microbiome theory ${ }^{9,12}$. This theory proposed that factors such as cesarean section, shorter breastfeeding, maternal use of 


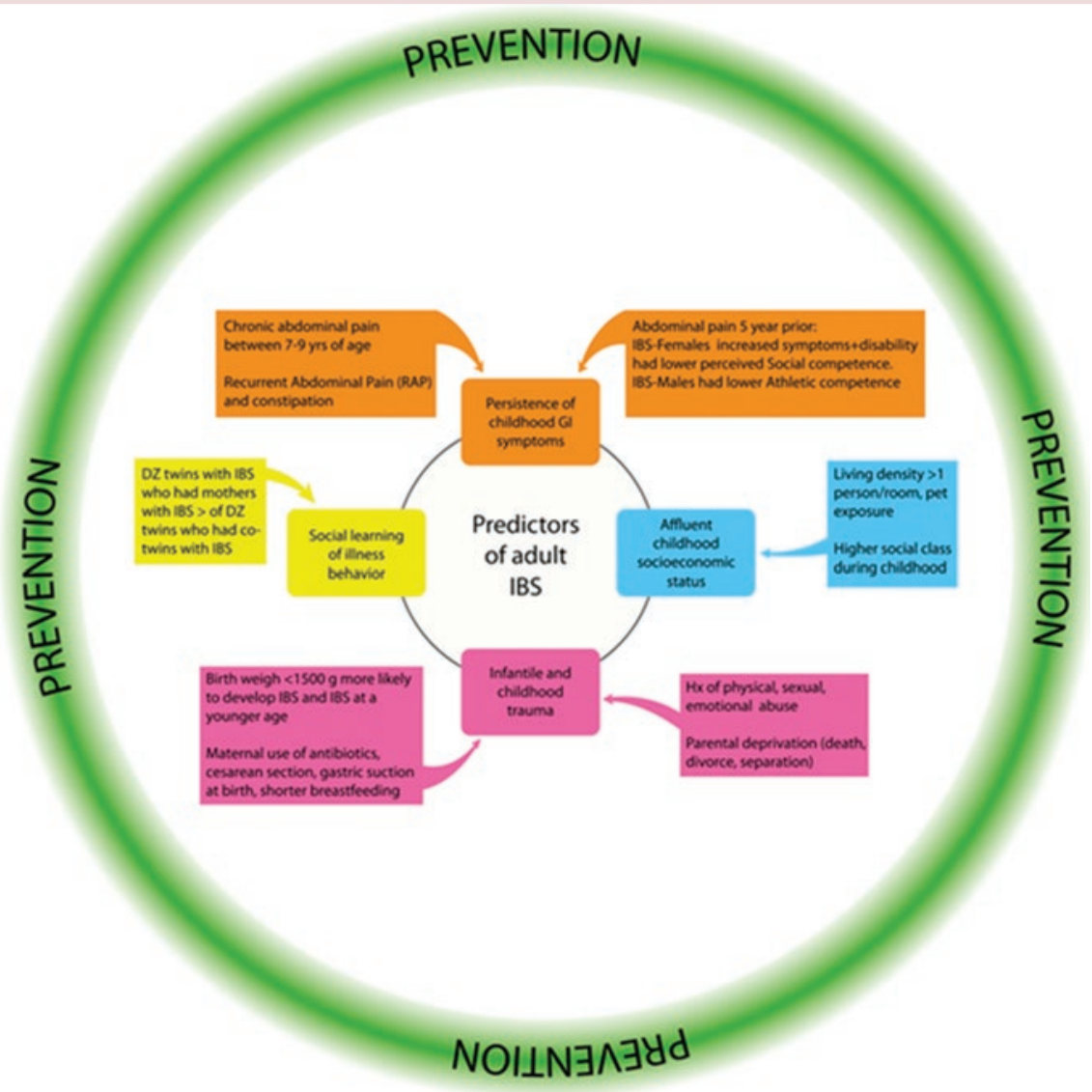

FigurE 1. Early risk factors that contribute to IBS in adolescents and adults. The figure depicts the four main categories of early life factors for developing IBS in adulthood as described by Chitkara et al. Persistence of childhood gastrointestinal symptoms into adulthood, affluent childhood socioeconomic status, infantile and childhood trauma, and social learning of illness behavior, where the main categories of their analysis that predicted IBS in adulthood ${ }^{9}$. In addition, rather than treating patients once they consult for their symptoms, the novel approach is prevention, including cope with stressful situations, confiding in others, identifying dysbiosis profiles, diet, and probiotics among others, which need to be further investigated.

antibiotics and formula feeding in the babies among others, impair gut-microbiota colonization, and immunoregulation EL, predisposing for later development of inflammatory conditions such as the low-grade inflammation that may be present in $\mathrm{IBS}^{12}$. Other traumatic factors EL that were related to the development of IBS in adulthood included a history of physical, sexual, and/or emotional abuse and parental deprivation due to death of a parent, divorce, or separation ${ }^{9}$ (Fig. 1).
Several years later, in a randomly selected group of residents from Olmsted County, Minnesota that participated in different surveys conducted in 1988-1990, 2002-2003, and 2007-2008, the overall IBS-Rome III prevalence was found at $16.2 \%(95 \% \text { CI: } 15.3-17.4)^{13}$. Interestingly, in this study, a birth cohort phenomenon relation was found in the prevalence of IBS, as this DGBI was significantly more likely among individuals that were born between 1963 and 1972, OR: 2.6 (95\% CI: 0.97-7.0), p = 0.058 . The authors did not believe that this 
relationship was due to factors such as childhood abuse and violence, ${ }^{14}$ as the presence of such issues was lower during that decades ${ }^{13,15}$. In contrast, they suggested that this birth-cohort relationship with IBS could be related to lower birth weight that had an increased incidence in the United States during the same years $^{16}$. They hypothesized that low birth weight could have played a role in the development of IBS due to inadequate maturation of the enteric and central nervous system. Furthermore, low birth weight may affect gut motility, another factor that has been related to IBS ${ }^{17}$. In addition, breastfeeding hit its lowest prevalence in 1971, with just $24 \%$ of mothers breastfeeding in the hospital after delivery, and only $5.4 \%$ of mothers still breastfeeding at 6 months ${ }^{18}$. The latter could have impacted on the microbiota colonization of the gut, predisposing to IBS ${ }^{13,19}$. A British study also found a birth-cohort phenomenon with a significantly higher proportion IBS in the 1970 cohort compared with the 1958 cohort at 30 years of age (interviewed in $1999 / 2000)^{20}$.

A recently published study in a cohort of $1,963,685$ subjects born in Sweden between 1973 and 1992 that were followed-up until 2010 when they were 18-38-year-old, identified several early life risk factors for the development of IBS including a birth weight $<2500 \mathrm{~g}$, second in birth order, a fetal growth $\geq 1$ standard deviation, maternal age $>$ 20-year-old, a divorced or widowed mother, mother's education of 10-11 and 12-14 years, and parental history of IBS, anxiety, or depression ${ }^{21}$. In addition, a higher number of risk factors increased the likelihood of having IBS in adulthood. In men, the hazard ratio (HR) increased to 2.3 if four risk factors were present, including being born by cesarean section + living alone + family history of anxiety + family history of IBS compared to men without any risk factors. In women, the HR increased to 6.38 if they were born with a cesarean section, + living alone + family history of anxiety + family history of IBS $^{21}$.

Infectious gastroenteritis has been identified as another important childhood factor related to the development of IBS later in life. Cremon et al. studied a randomly selected cohort of subjects that were exposed to an outbreak of Salmonella enteritidis Group D infected tuna sauce that was delivered to schools in Bologna-Italy, in October 1994. One hundred and thirty three subjects between 18 and 25-year-old out of 1811 individuals that were exposed as children at 3-10 years of age, and 71 subjects between 34 and 74 years of age out of 127 subjects exposed as adults, answered several questionnaires. It was found that IBS diagnosed by Rome II and Rome III criteria was significantly more prevalent among exposed versus non-exposed individuals. However, those exposed in childhood were at higher risk, 2.12 (1.21-3.71), $\mathrm{p}=0.008$; not those exposed as adults 1.59 (0.77-3.29), $\mathrm{p}=0.210$. Further, after multivariate analysis, increased prevalence of functional dyspepsia and increased levels of anxiety were significantly associated with post-infectious IBS (PI-IBS) ${ }^{22}$. There was no correlation with hospitalization, more than 7 days of the infectious enteritis episode, diarrhea, abdominal pain, vomiting, fever, headache, or use of antibiotics ${ }^{22}$. Another study in Germany found that children between 3 and 10 years of age with a history of Salmonella infection reported significantly more abdominal pain and headache ${ }^{23}$. 
Later, in a study by Koloski et al. in a random sample of 767 subjects in Sidney-Australia that previously responded a validated survey, the prevalence of IBS diagnosed per Rome III criteria was 17\% (95\% CI: 15-20), and among them, 20.2\% (95\% CI: 13.6-28.1) met criteria for PI-IBS ${ }^{12}$. PI-IBS was found to be associated with a history of sudden onset of bowel problems, a previous bout of gastroenteritis in the year before the first onset of bowel problems including a physician's diagnosis of gastroenteritis after stool tests, overseas travel at the time of the first onset of bowel problems, and antibiotic use during the 3 months before the first onset of stomach and bowel problems ${ }^{12}$. Proxy measures for microbial exposure-factors up to the age of 5 years such as sharing a bedroom and pet exposure, especially to herbivore ones including horses or birds, together with the subsequent exposure to enteric infections, were significantly associated with IBS in adulthood. The authors proposed that these findings provided indirect support for the disappearing microbiome theory rather than the hygiene hypothesis ${ }^{12}$. The disappearing microbiome theory may be related to impaired gut-microbiota colonization and immunoregulation EL, due to factors such as cesarean section, shorter breastfeeding (both found by Koloski et al. in their study), maternal use of antibiotics, and formula feeding in infants, and among others ${ }^{12}$. On the other hand, the hygiene hypothesis proposes that sanitation in infancy impairs microbiota colonization of the gut and immunoregulation ${ }^{11}$. The high rate of PI-IBS in the previous study is in contrast to the lower rates found in countries like Mexico, where roughly 5\% of the IBS patients meet criteria for PI-IBS ${ }^{24}$. In addition, a study to determine the carriage prevalence of parasites among individuals fulfilling criteria for IBS versus controls in Central America did not find any difference ${ }^{25}$. It is possible that in these countries, socioeconomic conditions such as sharing a bedroom EL, pet exposure, living in rural areas (non-hygiene factors) in a population with lower rates of cesarean section and gastric suctioning at birth and larger breastfeeding periods (non-disappearing microbiome factors), protect against the development of IBS after exposure to enteric infections, therefore, producing a low prevalence of PI-IBS later in life ${ }^{24}$.

\section{TRANSITION OF CARE}

The transition of adolescents from pediatric to adult care is a crucial moment in managing chronic diseases, and an inappropriate transition or the incomplete transmission of data from the pediatrician to the adult gastroenterologist can dramatically decrease compliance to treatment and prognosis of a young patient, particularly in the case of severe disorders ${ }^{26}$. However, literature on the transition of care for childhood and adolescence to adulthood is available mainly for inflammatory bowel disease, celiac disease or liver diseases, but it is scarce for IBS both in terms of patients related issues and healthcare provider programs for this transition ${ }^{26-28}$.

For example, in terms of patient-related issues, pubertal maturation has been analyzed in a study with Rome III-IBS children, ages 7-17-year-old recruited from both primary and tertiary clinics between January 2009 and January 2014. It was found that girls with higher Tanner scores (more mature pubertal 
development) had both decreased pain severity and pain interference; in contrast to boys with higher Tanner scores that had both increasing pain severity and pain interference $^{29}$. Furthermore, irrespective of pubertal status, girls had both increased somatic complaints and a higher percentage of hard stools (Bristol Stool Form Scale Type 1 or 2) versus boys. Pubertal status and sex did not significantly relate to IBS subtype, pain frequency, stooling frequency, anxiety, or depression. The authors suggested that these differences provide insight into the role of pubertal maturation during the transition from childhood to adult IBS ${ }^{29}$. However, the results of these studies contradict other studies that showed no increase in the prevalence of IBS in post-pubertal girls comparing with pre-pubertal girls ${ }^{30,31}$. Thus, the role of puberty and hormones in the development of IBS has to be further studied.

Gut microbiota dysbiosis has also been suggested as a risk and premorbid factors for the childhood-adulthood transition in IBS as well as in IBD, and it has been proposed that tracking dysbiosis supports new personalized/ stratified prevention programs, generating Decision Support System tools ${ }^{32}$.

As for health-care provider programs, no objective data are available to inform physicians about the most effective approach in the transition of care; nevertheless, in other fields of medicine are joint pediatric/adult transition clinics ${ }^{33}$. An effective transition is a process that should involve not only healthcare providers but also the family. Furthermore, social workers may facilitate the transition process as they are uniquely trained to complete biopsychosocial assessments to understand the needs of patients and families and address these issues ${ }^{34}$.

In medical care in general, it has been advocated that the transition of care process should start at 12 years of age making youth and family aware of it. At age 14, the transition planning should initiate at 16 , youth and parents need to be prepared for the adult model of care and discuss the transfer to make the transition at 18 years old ${ }^{35}$. This is important as seeing an adult provider is a novel experience and expectations may differ. Length and frequency of visits are shorter and less often compared to visits to pediatric care. Furthermore, the young adult may seek independence from family participation in their care. Later, between 18 and 22 years old, the transfer to adult specialists is done so that between 23 and 26 years of age the young adults are integrated into adult care ${ }^{35}$.

Web-based technology programs have been used to train adolescents with chronic diseases to develop independent disease self-management and learn to communicate effectively with their health-care team to transition from pediatric to adult-oriented health-care systems ${ }^{36}$. Furthermore, a scale that measures the health-care transition and self-management skills by youth with chronic health conditions has been developed ${ }^{37}$.

The transition of care is an important topic that deserves to be analyzed, and guidelines should be established considering that IBS is a chronic, long-standing disorder that may start in childhood and continue into adulthood, and diagnostic criteria may differ between children and adults ${ }^{38}$. Understanding 
risk factors that have been discussed previously, such as early life events, the role of family and enteric infections is important for the adult health-care provider ${ }^{9}$. Although there are no guidelines for the transition of care in DGBI, the recently published curriculum for neurogastroenterology and motility training from the joint American Neurogastroenterology and Motility Society and the European Society for Neurogastroenterology and Motility that was fully endorsed by the Australasian Neurogastroenterology and Motility Association, the Asian Neurogastroenterology Motility Association, the Sociedad Latinoamericana de Neurogastroenterologia, and the American Society for Gastrointestinal Endoscopy identified eleven training domains within $\mathrm{NGM}^{38}$. These consisted of functional gastrointestinal disorders, visceral hypersensitivity and pain pathways, motor disorders within anatomic areas (esophagus, stomach, small bowel and colon, and anorectum), mucosal disorders (gastro-esophageal reflux disease, and other mucosal disorders), consequences of systemic disease, consequences of therapy (surgery, endoscopic intervention, medications, and other therapy), and transition of pediatric patients into adult practice. To cover these domains, a 3-tiered training curriculum was proposed, Tier 1: NGM knowledge and training is expected of all gastroenterology trainees and practicing gastroenterologists; Tier 2: Knowledge and training is appropriate for trainees who anticipate NGM disorder management and NGM function test interpretation being an important part of their careers, which may require competency assessment and credentialing of test interpretation skills; and Tier 3: Knowledge and training is undertaken by trainees interested in a dedicated NGM career and may be restricted to specific domains within the broad NGM field ${ }^{38}$.

\section{NATURAL HISTORY AND SYMPTOM STABILITY OF IBS}

Several studies have analyzed the natural history of IBS symptoms. For instance, in 2007, Halder et al. analyzed the natural history of DGBI diagnosed according to Rome II criteria, over 12 years, in a longitudinal population-based study in Olmsted County, Minnesota ${ }^{39}$. Among 1365 surveyed subjects, the prevalence of IBS remained stable from beginning to end, 12 years later: $8.3 \%$ and $11.4 \%$. However, in general, $12-30 \%$ of the IBS patients (IBS with constipation, diarrhea: IBS-D, both: IBS-both, and IBS-no C or D), remained stable along time. Between 20\% and $35 \%$ became asymptomatic and about $40 \%$ changed to a different DGBI ${ }^{39}$. In another study in primary care over 10 years of follow-up in middle-aged patients (40-49 to 50-59-year-old) according to Manning criteria, IBS at baseline was present in 5.5\% (95\% CI: 5-6\%) and persisted in $67 \%$ (95\% CI: $61-73 \%$ ) of them. Likelihood of consultation of these patients was related to the presence of Helicobacter pylori infection, and any dyspepsia-related consultation. Female, use of nonsteroidal anti-inflammatory drugs or any IBS-related consultation, were borderline factors ${ }^{40}$.

In Iceland, a postal population-based study analyzed the performance of four IBS criteria in detecting incidence and stability of categories over a 10 -year period ${ }^{41}$. Questionnaires were mailed to the same age and gender-stratified random sample of the Icelandic population aged 18-75 years in 1996 and again in 2006. 
IBS varied according to Manning criteria, Rome II, Rome III, criteria with Manning showing the highest $(32 \%)$ and Rome II the lowest (5\%) prevalence ${ }^{41}$. Younger subjects and females were more likely to have IBS and prevalence was stable over 10 years for all criteria except Rome III. There was a turnover in all IBS subgroups and a strong correlation among IBS, functional dyspepsia, and heartburn ${ }^{41}$. Another study using a web panel representative of the Danish general population from 18 to 50 years of age using Rome III criteria for IBS, was conducted in January 2010, January 2011, and March 2013 ${ }^{42}$. The prevalence of IBS was $15.4 \%$, and the incidence was $10.3 \%$, 3 times higher for those with unspecific gastrointestinal symptoms compared to asymptomatic subjects. The vast majority of subjects fulfilling Rome III criteria for IBS reported gastrointestinal symptoms after 1 and 3 years ${ }^{42}$.

Finally, 40 IBS patients diagnosed by Rome III criteria (average age, 33 years old) and 40 controls (average 29.6 years old) without chronic digestive disorders, answered a questionnaire about the history of colic, chronic diarrhea, functional abdominal pain (FAP), constipation, and migraine in infancy and childhood ${ }^{43}$. Adults with IBS reported a significantly higher prevalence of chronic diarrhea and FAP in their childhood, than the control group. There were no differences in the presence of other childhood functional symptoms. Interestingly, when asked about the onset of symptoms that led to the diagnosis of IBS, they referred mostly beginning in adulthood and not linking their current diagnosis of IBS with their background in childhood $^{43}$. This kind of information supports the recommendation of the curriculum for neurogastroenterology and motility training ${ }^{38}$ that disorders in adults should be explained mentioning the whole lifespan which may help patients to understand the reasons for symptoms at the time of consultation.

\section{PREVALENCE OF IBS FROM YOUNG ADULTS TO OLDER AGE}

Whether the prevalence of IBS increases or decreases from childhood and adolescence to adulthood life, is a matter of controversy. It has been discussed that diagnostic criteria may have lower sensitivity at higher age or that there might be lower visceral sensitivity with increasing age. In fact a recent study from the Netherlands, published in abstract form, showed an age-related decrease in abdominal pain perception ${ }^{44}$. The authors suggested that this difference may be attributed to biological changes, such as decreased of the transient receptor potential Ankyrin 1 (TRPA1) expression in intestinal epithelium, as the gene transcription of TRPA1 was significantly lower in healthy elderly compared to young adults, whereas no significant difference was found for the capsaicin/vanilloid receptor 1 (TRPV1) ${ }^{44}$. IBS may be less important than other medical comorbidities present at an older age, or older patients may adjust more readily to IBS symptoms, and therefore, they might complain less of the IBS symptoms $^{38,45}$. On the other hand, IBS could be part of the natural course of aging or the impact of IBS may be amplified in older adults due to additive effects of multiple medical problems triggering worse health outcomes and psychological distress ${ }^{45}$.

Information on these issues is lacking, even in relation to the prevalence of IBS from younger to older age. In the meta-analysis of 
the global prevalence and risk factors of Lovell and Ford published six years ago, the pooled prevalence of IBS in subjects that were younger than 30 years old $(n=6909)$ was reported at $11.0 \%$ (95\% CI: 6.0-18.0). Although the prevalence seemed to decrease by age band of 10 years to $7.3 \%$ (95\% CI: 4.3-11.0), it did not reach statistical significance ${ }^{46}$. Notwithstanding, when compared in individuals older versus $>50$ year-old, the prevalence decreased significantly with an OR: 0.75 (95\% CI: 0.62-0.92) for IBS. There was significant heterogeneity between studies and evidence of funnel plot asymmetry or other small study effects ${ }^{46}$.

In a convenience sample-study of 1000 adults from nine sites in the metropolitan area of Mississippi-USA, including a medical center, churches, and a blood bank (670 African Americans, 320 Caucasians, and 10 others), the study sample was divided in two groups, younger and older of 50 years $^{47}$. The two age groups were similar with respect to gender and household income. Also, the IBS prevalence was similar in both groups $(<50: 9.9$ vs. $\geq 50$ : $7.6 \%$ ), irrespective of race, sex, marital status, size of household, location of residence (rural vs. urban), level of educational status, and household income. However, compared to the older group, there was a trend toward a higher prevalence of IBS among divorced subjects and in those with income below the poverty level in the younger subjects ${ }^{47}$. In contrast, older IBS patients were more likely to attend church regularly. There were no differences between the two groups in the history of traveler's diarrhea, food intolerance, drug allergies, health-care utilization in terms of a number of physician visits, use of prescription and alternative medications, and being disabled due to IBS. Neither was there any difference in the overall quality of life (QOL) according to the SF-12 questionnaire nor in its general health and physical functioning components. However, older IBS patients had better social functioning. Although IBS occurred less frequently among older than younger patients, the difference was not statistically significant and social functioning was actually better on average among older compared to younger IBS patients ${ }^{47}$.

Another study by Sayuk et al. that were designed to determine the difference in patients diagnosed with IBS-D versus subjects with non-diagnosed IBS, provided important information on this regard ${ }^{47}$. The sample was analyzed according to three groups: 18-39 years old, 40-50, and older than 60. The later age group had the lowest prevalence of diagnosed IBS-D compared to the others $(38 \%, 40 \%$, and $22 \%$ ). Furthermore, those with $>10$ years of symptom duration constituted the highest proportion compared to those with 5-10 years and $<5(50 \%, 20 \% \text {, and } 25 \% \text {, respectively })^{47}$. In addition, those with $>10$ years of IBS symptoms more frequently consulted to three or more physicians compared to the others and were the ones that had consulted more to gastroenterologists as well. The above figures suggest that IBS-D is less frequent at an older age, but these patients consult with higher frequency than the younger ones ${ }^{48}$.

Although IBS seems to vary across age, it is highly comorbid with other medical conditions. Therefore, Thakur et al. aimed at determining the moderating effect of age on the relationship between medical comorbidity and health outcomes in IBS patients. They found that age interacted with medical 
TABLE 1. Clinical issues and adverse events of IBS treatments according to age

\begin{tabular}{|l|l|l|}
\hline Medication & Clinical issues/adverse effects to consider & Age limit in years of patients included in clinical trials \\
\hline Antispasmodics & Narrow-angle glaucoma, urinary retention & --- \\
\hline Tricyclic antidepressants & $\begin{array}{l}\text { Constipation, cardiac arrhythmias, blurred vision, dry } \\
\text { mouth, urinary retention, autonomic dysfunction, } \\
\text { cognitive impairment }\end{array}$ & --- \\
\hline Loperamide & Fecal impaction & --- \\
\hline Laxatives & Diarrhea and dehydration & --- \\
\hline Tegaserod & Cardiovascular and neurological adverse effects & --- \\
\hline Lubiprostone & Nausea more frequent in patients $>65$ & Up to 82 \\
\hline Linaclotide & --- & Up to $83 ; 3-6 \%$ study subjects were $>65$ \\
\hline Plecanatide & Slightly more AE in $<65$ & Up to 82 \\
\hline Eluxadoline & Cardiovascular AE in $<70$ & $8 \%$ of study subjects were $<65$ \\
\hline Rifaximin & --- & Up to 85 \\
\hline$---:$ information not available & & \\
\hline
\end{tabular}

comorbidities to predict anxiety. Furthermore, anxiety was greater among patients with many comorbidities, with this effect being more pronounced for younger adults. Depression, also predicted by the interaction between age and comorbidities, showed the same pattern as anxiety. There was no significant interaction between age and medical comorbidities in predicting IBS symptom severity or IBS QOL ${ }^{49}$. These results showed that distress among IBS patients with medical comorbidities varies with age, with higher levels of anxiety and depression among younger adults than older patients. Finally, medical comorbidity may have a more selective impact on psychological distress, which may increase IBS burden for these patients and complicate its medical management ${ }^{49}$.

\section{TREATMENT OF IBS IN OLDER AGE}

Treatment of IBS in the elderly is similar to younger adult patients, but adjustments may be needed according to individual conditions. Medical issues that need to be considered have been reviewed by Kurniawan and Kolopaking ${ }^{45}$. As they rightfully state, aging itself is a red flag that needs to be considered, especially when IBS onset occurs at an older age and exclusion of organic diseases, using several investigations, is of paramount importance in older patients ${ }^{45}$. In fact, the American College of Gastroenterology and the British Society of Gastroenterology have published guidelines on red flags that have been adopted by the Rome Foundation for the investigation of patients with IBS, including documented unintentional weight loss, nocturnal symptoms, family history of colon cancer, blood mixed with stools, recent antibiotic use, relevant abnormalities on physical examination, short history of symptoms, and age older than 50 years old ${ }^{50-52}$.

In their review, Kurniawan and Kolopaking have suggested to consider systemic disorders such as diabetes mellitus and polypharmacy 
that may cause alterations in pain perception; rule out mesenteric ischemia, thyroid dysfunction, and autonomic neuropathy that may mimic symptoms of IBS. Furthermore, changes in bowel habit are frequently intermittent at an older age; women have a higher prevalence of perineal descent which is associated with difficulty in evacuation and chronic prostatitis in men may cause abdominal pain, difficult evacuation or intermittent diarrhea that may be confused with IBS symptoms ${ }^{45}$.

Few clinical trials have analyzed the outcomes and adverse effects according to age groups. Table 1 depicts currently used treatment for IBS and conditions in which adjustments are needed as well as differences in adverse events according to age-groups. It is interesting that analyses of adverse events have only been done in clinical trials of the most recent and modern treatments for IBS.

\section{PREVENTIVE MEASUREMENTS}

A recent study among 197 IBS patients and 165 healthy controls confirmed a greater number of Early Adverse Life events (EALs) and higher perceived trauma severity in association with increased odds of IBS $^{6}$. In addition, they aimed at determining if confiding in others reduces the odds of IBS and if the number, trauma severity, and first age of EALs are associated with symptom severity and sex differences. Subjects completed the Childhood Traumatic Events Scale, measuring the severity of EALs and degree of confiding in others ${ }^{6}$. Confiding in others decreased the odds of having IBS, however, the first age of EALs was not a predictive factor, and there were no differences according to sex. The authors concluded that assessing the traumatic severity of EALs and amount of confiding in others is important as they can affect the risk of having IBS $^{6}$. Their findings emphasize early interventions to improve health outcomes in individuals with EALs, for example, to prevent IBS.

Moreover, the publication of studies showing that EALs occurring during the neonatal period, infancy and childhood predispose to the development of DGBI later in life has led investigators to propose a novel approach to the standard of care. At present, DGBI are treated once the patient presents for consultation with symptoms that are severe enough to prompt patients and families to seek medical attention. This approach is associated with suboptimal results with one in four children evolving into adults with IBS. The newly proposed paradigm is intended at preventing the onset of DGBI shifting the focus from treating after symptoms develop ${ }^{53,54}$. Traumatic events, gastrointestinal inflammation, i.e. cow's milk protein allergy in infancy ${ }^{55}$, Henoch-Schonlein purpura in childhood ${ }^{56}$, gastrointestinal ${ }^{57}$ and extraintestinal infections, i.e. urinary tract infection in the $1^{\text {st }}$ year of life ${ }^{58}$ and gastric suction at birth ${ }^{59}$, abdominal surgery, i.e. pyloric stenosis and umbilical hernia ${ }^{60,61}$ have all been associated with the onset of DGBI. Recently, the results of some of the initial cohort retrospective studies that showed the association of cow's milk protein allergy ${ }^{62,63}$, urinary infection, ${ }^{64}$ and Henoch-Schonlein purpura ${ }^{65}$, with FAP disorders in children have been replicated in studies with a different design and sample including large population studies. Thus, the diagnosis of these conditions can be seen as an opportunity to intervene (primary 
prevention). In addition, the early treatment of children with initial symptoms can result in secondary prevention (i.e. obesity ${ }^{66}$ and anxiety $^{67}$ ) avoiding the long-term consequences of these disorders into childhood and/or adulthood. No trials have yet been published in humans but animal studies have shown that the use of probiotics in the neonatal period can prevent visceral hyperalgesia ${ }^{68}$, and one unpublished trial in a school in Chicago (Saps et al. - personal communication) has found that an intervention aimed at helping cope with stressful situations in healthy school children can lower the incidence of abdominal pain, headaches, and school absenteeism.

Future interventions to reduce the incidence of IBS may also include identifying populations at risk by including those with high risk of flare-up recurrence (omics-based dysbiosis profiles); microbial and molecular biomarkers of health and disease; omics-based pipelines for laboratory medicine diagnostics; and health apps for self-management of score-based dietary profiles, which can be shared with clinicians for nutritional habit and lifestyle amendment; and omics profiling data warehousing and public repositories for IBD and IBS profile consultation. The above can represent novel laboratory and clinical tools that can be used for preventing or postponing IBS ${ }^{32}$.

In summary, there is increasing interest in the prevention of IBS with a larger number of experts believing that prevention should be the intervention of the future. Thus, future longitudinal studies should investigate whether this newly proposed approach is successful in decreasing the incidence and prevalence of DGBI in children and adults.

\section{CONCLUSIONS}

Multiple EALs have been related to IBS later in adulthood including chronic abdominal pain, social learning of illness behavior, and infantile and childhood trauma, intestinal and extra-intestinal infections and inflammation, abdominal surgery, use of antibiotics, birth weight $<1500 \mathrm{~g}$ (possibly associated to a greater likelihood of maternal separation, cesarean section, painful interventions, surgeries, use of antibiotics, intestinal inflammation, and among other factors), gastric suctioning and cesarean section (may impair gut-microbiota colonization and immunoregulation: disappearing microbiome), history of abuse, parental deprivation, and low socioeconomic status. There is a controversy of early enteric infections as some data have shown that they predisposed to PI-IBS in adulthood, while other studies suggest that they may be protective against the development of PI-IBS later in life. The same holds true for pet exposure and higher living density (hygiene factors). However, it is possible that infections EL in patients with the presence of factors associated with the disappearing microbiome theory, may be predisposed to PI-IBS, contrary to their absence. As for the transition of care from pediatric to adult care - crucial in managing a chronic disorder - there is no experience in IBS as with other gastrointestinal diseases. Whether the prevalence of IBS increases or decreases with age, the data are inconsistent; however, at least a third of IBS patients become asymptomatic, a third remain stable, and the remaining evolve into another DGBI along time. It is also important to consider that distress among IBS patients with medical comorbidities varies with age, with 
higher levels of anxiety and depression among younger adults than older patients. And finally, treatment of IBS at an older age is similar to that in younger adult patients, however, adjustments may be required according to organic comorbidities.

In conclusion, AELs need to be identified to establish preventive measurements for IBS later in life. The large number of adolescents that becomes young adults with DGBI requires coordination of care between pediatric and adult gastroenterologists, harmonization of terminology when possible and collaborative studies that include pre-term and fullterm neonates, infants, children, adolescents, and adults of various ages. Factors related to pregnancy that could influence the newborn and the future development of IBS and the variation in response to treatment among age groups should also be investigated. The transition of care guidelines need to be developed for IBS, and other DGBI and treatment adjustments may be needed according to comorbidities in older patients.

\section{ACKNOWLEDGMENTS}

We thank Omar Agni García Hernández, from the Unidad de Investigación en Medicina Experimental, Facultad de Medicina - Universidad Nacional Autónoma de México (UNAM), for his support in the preparation of this manuscript.

\section{POTENTIAL CONFLICTS OF INTEREST}

Max Schmulson: during the past year has been a Member of the Advisory Board of
Alfa-Sigma Mexico, and a Consultant for Commonwealth Diagnostics International Inc. Furthermore, a speaker for Alfa-Sigma Mexico and Takeda Mexico.

Miguel Saps: has served as a consultant for QOL Medical.

\section{FUNDING}

No funding was received in the preparation of this manuscript.

\section{REFERENCES}

1. Drossman DA, Hasler WL. Rome IV-functional GI disorders: disorders of gut-brain interaction. Gastroenterology. 2016;150:1257-61.

2. Sperber AD, Dumitrascu D, Fukudo S, et al. The global prevalence of IBS in adults remains elusive due to the heterogeneity of studies: a Rome foundation working team literature review. Gut. 2017;66:1075-82.

3. Devanarayana NM, Rajindrajith S. Irritable bowel syndrome in children: current knowledge, challenges and opportunities. World J Gastroenterol. 2018;24:2211-35.

4. Korterink JJ, Diederen K, Benninga MA, Tabbers MM. Epidemiology of pediatric functional abdominal pain disorders: a meta-analysis. PLoS One. 2015;10:e0126982.

5. Park SH, Videlock EJ, Shih W, et al. Adverse childhood experiences are associated with irritable bowel syndrome and gastrointestinal symptom severity. Neurogastroenterol Motil. 2016;28:1252-60.

6. Ju T, Naliboff BD, Shih W, et al. Risk and protective factors related to early adverse life events in irritable bowel syndrome. J Clin Gastroenterol. 2018.

7. Wikipedia. Young Adult (Psychology); 2018. Available from: https://www. en.wikipedia.org/wiki/Young_adult_(psychology).

8. Wikipedia. Old Age; 2018. Available from: https://www.en.wikipedia.org/ wiki/Old_age.

9. Chitkara DK, van Tilburg MA, Blois-Martin N, Whitehead WE. Early life risk factors that contribute to irritable bowel syndrome in adults: a systematic review. Am J Gastroenterol. 2008;103:765-74.

10. Levy RL, Jones KR, Whitehead WE, et al. Irritable bowel syndrome in twins: heredity and social learning both contribute to etiology. Gastroenterology. 2001;121:799-804.

11. Bloomfield SF, Stanwell-Smith R, Crevel RW, Pickup J. Too clean, or not too clean: the hygiene hypothesis and home hygiene. Clin Exp Allergy. 2006;36:402-25.

12. Koloski NA, Jones M, Weltman M, et al. Identification of early environmental risk factors for irritable bowel syndrome and dyspepsia. Neurogastroenterol Motil. 2015;27:1317-25.

13. Brummond NR, Locke GR $3^{\text {rd }}$, Choung RS, et al. Effects of birth cohorts on the irritable bowel syndrome support early-life risk factors. Dig Dis Sci. 2015;60:2112-8

14. Talley NJ, Fett SL, Zinsmeister AR. Self-reported abuse and gastrointestinal disease in outpatients: association with irritable bowel-type symptoms. Am J Gastroenterol. 1995;90:366-71. 
15. Finkelhor D, Turner H, Ormrod R, Hamby SL. Trends in childhood violence and abuse exposure: evidence from 2 national surveys. Arch Pediatr Adolesc Med. 2010;164:238-42.

16. Brosco JP, Sanders LM, Guez G, Lantos JD. Historical trends in low birth weight. Arch Pediatr Adolesc Med. 2010;164:99-100.

17. Berseth CL. Gestational evolution of small intestine motility in preterm and term infants. J Pediatr. 1989;115:646-51.

18. Ryan AS, Wenjun Z, Acosta A. Breastfeeding continues to increase into the new millennium. Pediatrics. 2002;110:1103-9.

19. Lee BJ, Bak YT. Irritable bowel syndrome, gut microbiota and probiotics. J Neurogastroenterol Motil. 2011;17:252-66.

20. Ehlin AG, Montgomery SM, Ekbom A, Pounder RE, Wakefield AJ. Prevalence of gastrointestinal diseases in two british national birth cohorts. Gut. 2003;52:1117-21.

21. Waehrens R, Li X, Sundquist J, Sundquist K, Zöller B. Perinatal and familial risk factors for irritable bowel syndrome in a Swedish national cohort. Scand J Gastroenterol. 2018;53:559-66.

22. Cremon C, Stanghellini V, Pallotti F, et al. Salmonella gastroenteritis during childhood is a risk factor for irritable bowel syndrome in adulthood. Gastroenterology. 2014;147:69-77.

23. Schwille-Kiuntke J, Unverdorben A, Weimer K, et al. Bacterial infections in childhood: a risk factor for gastrointestinal and other diseases? United European Gastroenterol J. 2015;3:31-8.

24. Schmulson M. Is post infection-irritable bowels syndrome less frequent in Mexico? Am J Gastroenterol. 2019.

25. Morgan DR, Benshoff M, Cáceres M, et al. Irritable bowel syndrome and gastrointestinal parasite infection in a developing nation environment. Gastroenterol Res Pract. 2012;2012:343812.

26. Italian Society of Paediatric Gastroenterology, Hepatology and Nutrition (SIGENP), Italian Association of Hospital Gastroenterologists and Endoscopists (AIGO), Italian Society of Endoscopy (SIED), Italian Society of Gastroenterology (SIGE), Elli L, Maieron R, et al. Transition of gastroenterological patients from paediatric to adult care: a position statement by the italian societies of gastroenterology. Dig Liver Dis. 2015;47:734-40.

27. Pinzon JL, Jacobson K, Reiss J. Say goodbye and say hello: the transition from pediatric to adult gastroenterology. Can J Gastroenterol. 2004;18:735-42.

28. de Silva PS, Fishman LN. The transition of the gastrointestinal patient from pediatric to adult care. Pediatr Clin North Am. 2017;64:707-20.

29. Chumpitazi BP, Weidler EM, Czyzewski DI, et al. Childhood irritable bowel syndrome characteristics are related to both sex and pubertal development. J Pediatr. 2017;180:141-70.

30. Blom PJ, Lu PL, Benninga MA, et al. The role of puberty in the development of pediatric functional gastrointestinal disorders: a population-based case-control study. Gastroenterology. 2017;152:S709.

31. Lu PL, Velasco-Benítez CA, Saps M. Sex, age, and prevalence of pediatric irritable bowel syndrome and constipation in colombia: a population-based study. J Pediatr Gastroenterol Nutr. 2017;64:e137-41.

32. Putignani L, Del Chierico F, Vernocchi P, et al. Gut microbiota dysbiosis as risk and premorbid factors of IBD and IBS along the childhood-adulthood transition. Inflamm Bowel Dis. 2016;22:487-504.

33. Moreno Villares JM. Transition to adult care for children with chronic neurological disorders; Which is the best way to make it? Nutr Hosp. 2014;29 Suppl 2:32-7.

34. Shanske S, Arnold J, Carvalho M, Rein J. Social workers as transition brokers: facilitating the transition from pediatric to adult medical care. Soc Work Health Care. 2012;51:279-95.

35. Health. TNAtAA. Got Transition. The National Alliance to Advance Adolescent Health; 2018. Avilable from: https://www.gottransition.org/.

36. Huang JS, Terrones L, Tompane T, et al. Preparing adolescents with chronic disease for transition to adult care: a technology program. Pediatrics. 2014;133:e1639-46.

37. Ferris ME, Harward DH, Bickford K, et al. A clinical tool to measure the components of health-care transition from pediatric care to adult care: the UNC TR(x)ANSITION scale. Ren Fail. 2012;34:744-53.
38. Gyawali CP, Savarino E, Lazarescu A, et al. Curriculum for neurogastroenterology and motility training: a report from the joint ANMS-ESNM task force. Neurogastroenterol Motil. 2018;30:e13341.

39. Halder SL, Locke GR $3^{\text {rd }}$, Schleck CD, et al. Natural history of functional gastrointestinal disorders: a 12-year longitudinal population-based study. Gastroenterology. 2007;133:799-807.

40. Ford AC, Forman D, Bailey AG, Axon AT, Moayyedi P. Irritable bowel syndrome: a 10-yr natural history of symptoms and factors that influence consultation behavior. Am J Gastroenterol. 2008;103:1229-39.

41. Olafsdottir LB, Gudjonsson H, Jonsdottir HH, Thjodleifsson B. Stability of the irritable bowel syndrome and subgroups as measured by three diagnostic criteria-a 10-year follow-up study. Aliment Pharmacol Ther. 2010; 32:670-80.

42. Krogsgaard LR, Engsbro AL, Jones MP, Bytzer P. The epidemiology of irritable bowel syndrome: symptom development over a 3-year period in Denmark. A prospective, population-based cohort study. Neurogastroenterol Motil. 2017;29:e12986.

43. Marugán-Miguelsanz JM, Ontoria M, Velayos B, et al. Natural history of irritable bowel syndrome. Pediatr Int. 2013;55:204-7.

44. Wilms E, Jonkers D, Keszthelyi D, et al. Age-related changes in abdominal pain in healthy individuals and irritable bowel syndrome (IBS) patients. Neurogastroenterol Motil. 2018;30 Suppl 1:64.

45. Kurniawan I, Kolopaking MS. Management of irritable bowel syndrome in the elderly. Acta Med Indones. 2014;46:138-47.

46. Lovell RM, Ford AC. Global prevalence of and risk factors for irritable bowel syndrome: a meta-analysis. Clin Gastroenterol Hepatol. 2012; 10:712-210000.

47. Minocha A, Johnson WD, Abell TL, Wigington WC. Prevalence, sociodemography, and quality of life of older versus younger patients with irritable bowel syndrome: a population-based study. Dig Dis Sci. 2006;51:446-53.

48. Sayuk GS, Wolf R, Chang L. Comparison of symptoms, healthcare utilization, and treatment in diagnosed and undiagnosed individuals with diarrhea-predominant irritable bowel syndrome. Am J Gastroenterol. 2017; 112:892-9.

49. Thakur ER, Quigley BM, El-Serag HB, Gudleski GD, Lackner JM. Medical comorbidity and distress in patients with irritable bowel syndrome: the moderating role of age. J Psychosom Res. 2016;88:48-53.

50. American College of Gastroenterology Task Force on Irritable Bowel Syndrome, Brandt LJ, Chey WD, et al. An evidence-based position statement on the management of irritable bowel syndrome. Am J Gastroenterol. 2009; 104 Suppl 1:S1-35.

51. Spiller R, Aziz Q, Creed F, et al. Guidelines on the irritable bowel syndrome: mechanisms and practical management. Gut. 2007;56:1770-98.

52. Drossman DA, Chang L, Chey WD, et al. Rome IV Functional Gastrointestinal Disorders-Disorders of Gut-Brain Interaction. Durham, NC: BW and A Books, Inc.; 2016.

53. Saps M, Langhaw A. An ounce of prevention may be worth many pounds of cure. J Pediatr. 2018;195:13-5.

54. Lu PL, Saps M. Functional gastrointestinal disorders: all roads lead to prevention. Clin Gastroenterol Hepatol. 2018;16:814-6.

55. Saps M, Lu P, Bonilla S. Cow's-milk allergy is a risk factor for the development of FGIDs in children. J Pediatr Gastroenterol Nutr. 2011;52:166-9.

56. Saps M, Dhroove G, Chogle A. Henoch-schonlein purpura leads to functional gastrointestinal disorders. Dig Dis Sci. 2011;56:1789-93.

57. Saps M, Pensabene L, Di Martino L, et al. Post-infectious functional gastrointestinal disorders in children. J Pediatr. 2008;152:812-6, 816.e1.

58. Rosen JM, Kriegermeier A, Adams PN, Klumpp DJ, Saps M. Urinary tract infection in infancy is a risk factor for chronic abdominal pain in childhood. J Pediatr Gastroenterol Nutr. 2015;60:214-6.

59. Anand KJ, Runeson B, Jacobson B. Gastric suction at birth associated with longterm risk for functional intestinal disorders in later life. J Pediatr. 2004;144:449-54.

60. Saps M, Bonilla S. Early life events: infants with pyloric stenosis have a higher risk of developing chronic abdominal pain in childhood. J Pediatr. 2011;159:551-40. 
61. Rosen JM, Adams PN, Saps M. Umbilical hernia repair increases the rate of functional gastrointestinal disorders in children. J Pediatr. 2013;163:1065-8.

62. Di Nardo G, Cremon C, Frediani S, et al. Allergic proctocolitis is a risk factor for functional gastrointestinal disorders in children. J Pediatr. 2018; 195:128-330.

63. Tan TK, Chen AC, Lin CL, et al. Preschoolers with allergic diseases have an increased risk of irritable bowel syndrome when reaching school age. J Pediatr Gastroenterol Nutr. 2017;64:26-30.

64. Tan TK, Saps M, Lin CL, Wei CC. Risks of irritable bowel syndrome in children with infantile urinary tract infection: a 13-year nationwide cohort study. J Investig Med. 2018;66:998-1003.
65. Kisla Ekinci RM, Balcı S, Mart OO, et al. Is henoch-schönlein purpura a susceptibility factor for functional gastrointestinal disorders in children? Rheumatol Int. 2019;39:317-22.

66. Bonilla S, Wang D, Saps M. Obesity predicts persistence of pain in children with functional gastrointestinal disorders. Int J Obes (Lond). 2011;35:517-21.

67. Lavigne JV, Saps M, Bryant FB. Models of anxiety, depression, somatization, and coping as predictors of abdominal pain in a community sample of school-age children. J Pediatr Psychol. 2014;39:9-22.

68. Kannampalli P, Pochiraju S, Chichlowski M, et al. Probiotic Lactobacillus rhamnosus GG (LGG) and prebiotic prevent neonatal inflammation-induced visceral hypersensitivity in adult rats. Neurogastroenterol Motil. 2014;26:1694-704. 